\title{
- L ALBAÑIL JOSÉ URBISO Y SU DECISIVA CONTRIBUCIÓN A LA CONSTRUCCIÓN DE LA IGLESIA DEL COLEGIO DE LA COMPAÑÍA DE JESÚS DE CALATAYUD
}

\author{
DAVID MIGUEL NAVARRO CATALÁN \\ Departamento de Composición Arquitectónica. Universitat Politècnica de València \\ danaca@cpa.upv.es \\ NAIKE MENDOZA MAEZTU \\ Doctora en Historia del Arte \\ mendozanaike@gmail.com
}

\begin{abstract}
Resumen: La iglesia del colegio de la Compañía de Jesús de Calatayud presenta un dilatado proceso constructivo y decorativo que abarca desde el siglo XVII hasta el XVIII. Este artículo profundiza en sus diferentes fases históricas aportando documentación inédita en la que destaca la capitulación de la nave de la iglesia con el albañil José Urbiso. En sus obras intervienen un gran número de artífices entre los que se incluye un grupo de miembros de la Compañía cuya actividad era ignorada hasta el momento como la del hermano José Iraola. Además, el descubrimiento del proyecto redactado por el hermano Antonio Ambrosio contribuye a incrementar el conocimiento de nuevos arquitectos miembros de la Compañía en el ámbito de la antigua provincia jesuita de Aragón.
\end{abstract}

Palabras clave: Calatayud / jesuitas / Urbiso / Ambrosio / barroco / Aragón.

\section{THE CRAFTMEN JOSÉ URBISO AND HIS DECISIVE CONTRIBUTION TO THE CONSTRUCTION OF THE CHURCH OF THE SOCIETY OF JESUS COLLEGE IN CALATAYUD}

\begin{abstract}
The church of the Society of Jesus college in Calatayud presents an extensive constructive and decorative process that takes from the 17 th to the 18 th century. This article goes in depth into its different historical phases revealing unpublished documentation, such as the contract for the church's nave with the mason José Urbiso. A great number of craftsmen intervened in its works, including a group of the Company members, whose activity was ignored until now like brother's José Iraola. Additionally, the discovered project elaborated by brother Antonio Ambrosio contributes to increase the knowledge of new architects that were Company members in the sphere of the old Jesuit province of Aragon.
\end{abstract}

Key words: Calatayud / Jesuits / Urbiso / Ambrosio / Baroque / Aragón.

La construcción del nuevo colegio de la Compañía de Jesús de Calatayud comienza poco tiempo después de que la orden acepte el encargo de las Escuelas de la Ciudad concertado en 1595. A su llegada a la ciudad, los jesuitas ocuparon unas casas que no abandonarán hasta la mudanza al sitio de- finitivo del colegio, efectuada el 7 de agosto de $1600 .^{1}$ La firma del contrato entre la Compañía de Jesús y la Ciudad -por el cual estos se hicieron cargo de la enseñanza de la gramática- les valió la propiedad de unas casas "vulgarmente dichas del estudio mayor", situadas en la parroquia y plaza

\footnotetext{
* Fecha de recepción: 15 de enero de 2019 / Fecha de aceptación: 25 de octubre de 2019.

1 Libro de bienes raizes y cabreo general del Colegio de la Compañia de Jesus de Calatayud. Sitio de este Colegio de Calatayud, Archivo Histórico Nacional (AHN), Clero, Jesuitas, lib. 587, p. 802.
} 


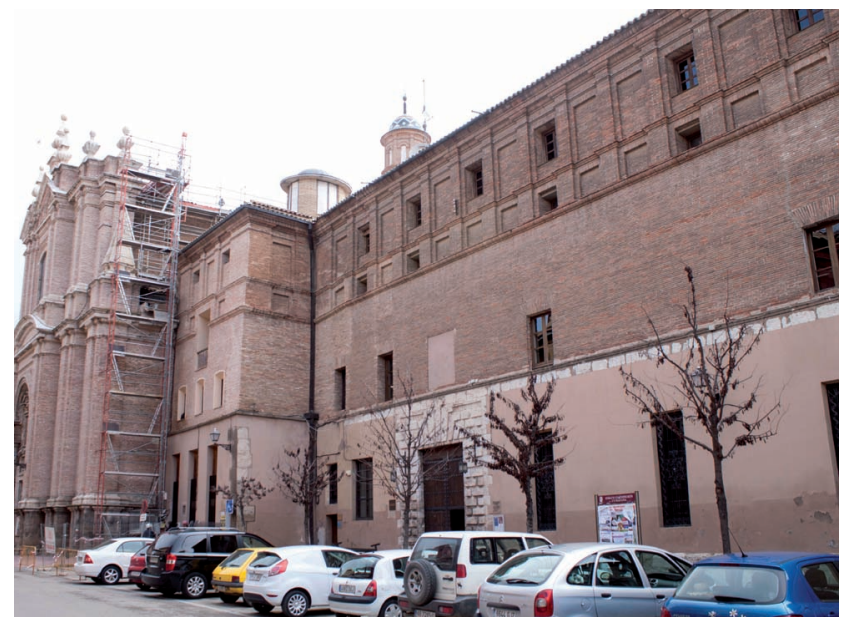

Fig. 1. Calatayud (Zaragoza). Antiguo Colegio de la Companía. Vista general.

de San Salvador de Calatayud. ${ }^{2}$ Transcurrido un mes después de la apertura de las Escuelas de gramática en 1595, el general Claudio Aquaviva dará su aprobación para que la obra del colegio de Nuestra Señora del Pilar comenzara en la primavera de $1596 .^{3}$

La construcción de la parte colegial de la casa jesuita bilbilitana se prolongará hasta la década de $1630,{ }^{4}$ por lo que, en la década siguiente, los es- fuerzos constructivos podrán dirigirse a comenzar la fábrica de una nueva iglesia. El templo de San Salvador, que había sido donado por el obispo Diego de Yepes a la Compañía de Jesús a comienzos del siglo XVII, será utilizado como iglesia provisional hasta la década de $1640 .^{5}$ La creciente popularidad de la orden en la ciudad hizo que el número de fieles fuera progresivamente en aumento, quedando pronto esta iglesia "pequeña e incapaz". Así, en 1644 el Concejo y la Universidad de Calatayud permitieron al colegio llevar a cabo la ampliación del templo. Asimismo, dieron facultad para que "en la fabrica de la nueba Iglessia se tomase todo lo que fuere necesario de las Calles y Plazas que circundan la Iglessia porque aquella quedase a esquadra y segun arte de Architectura". ${ }^{6}$ Sin embargo, las obras del templo tardaron en concluirse: hubo que esperar hasta 1756 para ver la iglesia finalizada, quedando su decoración inacabada en el momento de la Expulsión, cuando restaban por construir la torre y la portada, edificadas años después. ${ }^{7}$

\section{El proyecto del hermano Antonio Ambrosio (c. 1650)}

En 1650 el padre provincial Francisco Franco dio orden de ejecutar una traza del templo que fue diseñada, en torno a esa fecha, por un coadjutor de la Compañía, el hermano Antonio Ambrosio. ${ }^{8}$ Este jesuita, de origen italiano, estuvo en el colegio de Calatayud en 1651 y 1652, años en los que se ocuparía

2 Escuelas de la ciudad, ARSI, Fondo Gesuitico, Collegia, 1381, Calatayud, 10a, s. n. San Salvador fue una parroquia pequeña durante los siglos XIII y XIV. La iglesia sufrió especialmente en la Guerra de los Dos Pedros (1356-1369), siendo arrasada al estar en primera línea de combate. Con su extinción, su feligresía se integró con la de San Pedro de los Francos (MORALES GÓMEZ, Juan José, 2010-2011, pp. 168-170).

3 Carta del General Claudio Aquaviva al padre Pedro del Villar, 21 nov. 1595, ARSI, Arag. 6 I, Epístolas generales, f. 134r.

${ }^{4}$ El proceso de construcción de la parte colegial destinada a residencia y escuelas, del que poco se conoce, será expuesto con detalle en futuros trabajos.

5 Libro de bienes raizes y cabreo general del Colegio de la Compañia de Jesus de Calatayud. Sitio de este Colegio de Calatayud. Con una breve memoria de su fundacion, AHN, Clero, Jesuitas, lib. 587, pp. 803-804; Hist. et fundatio collegiorium Aragon 1561-1702 I, Prosecución de la Historia del Colegio de Calatayud, ARSI, Arag. 23 I, ff. 171-171 bis v; ARV, Clero, 1488, Anua 1600 , f. 56r. Deben corregirse las informaciones aportadas por A. Rubio Semper, que indica que esta iglesia se amplió entre 1622 y 1624, encargándose de los trabajos el obrero de villa bilbilitano Martín de Sagastiberry (RUBIO SEMPER, Agustín, 1980, pp. 36-37). Sin embargo, estas obras se refieren al Convento de San Juan de Letrán, y no al Colegio de Nuestra Señora del Pilar, como se ha venido afirmando hasta ahora (AHPNC, Miguel de Ciria, 1622, ff. 902r-902v; AHPNC, Miguel de Ciria, 1624, ff. 741v745v; AHPNC, Miguel de Ciria, 1626. f. 311v). Así lo confirma J. Martínez Verón, que sitúa a Sagastiberry como responsable de la construcción de la capilla mayor de la iglesia del Convento de San Juan de Letrán en Calatayud (1622), de las obras de su finalización (1624) y de otras obras de reforma en el mismo (1629). MARTíNEZ VERÓN, Jesús, 2000-2001, vol. IV, p. 409.

${ }^{6}$ El espacio y las condiciones necesarias para ello se estipularon el 7 de julio de 1644 ante el notario Miguel Jerónimo de Rada. La donación se hizo efectiva el 24 de julio ante el mismo notario (Libro de bienes raizes y cabreo general del Colegio de la Compañia de Jesus de Calatayud. Sitio de este Colegio de Calatayud, AHN, Clero, Jesuitas, lib. 587, p. 812).

7 Una síntesis del proceso constructivo de la iglesia: CRIADO MAINAR, Javier, 2010, pp. 272-274.

8 "6. Supuesto que habiéndose consultado los oficiales peritos en obras todos han juzgado convenir que se ejecute la traza del Hermano Antonio Ambrosio y que se haga la iglesia en el puesto que él señala y dello no se haga inconveniente alguno, antes muchas conveniencias; y que consideraba, y vistas todas cosas se juzgó en tan plena consulta nómine discepante, y que es con aplomo universal de toda la ciudad, ejecútese puntualmente" (Memorial del padre Francisco Franco, 19 sep. 1650, AHSIC, ACOB 007, s. f.). 
de encaminar esta obra, al mismo tiempo que acudía en diversas ocasiones a Salamanca para dar su parecer acerca del edificio del colegio Real que la orden estaba construyendo en dicha ciudad. ${ }^{9}$

La traza que el hermano Ambrosio diseñó para la iglesia bilbilitana -no conservada-, fue mostrada a otros oficiales de la construcción, con los que se consultó tanto su conveniencia, como la idoneidad del lugar elegido para la elevación de la fábrica. ${ }^{10}$

El padre Francisco Franco ordenó entonces a los jesuitas bilbilitanos solicitar limosna para sufragar la construcción de esta nueva iglesia, tal y como se había hecho en el colegio de Tarazona, una vez comenzadas las obras de su templo. ${ }^{11}$ Sin embargo, el dinero disponible inicialmente para ello resultaba, una vez más, insuficiente, a pesar de lo cual, el Viceprovincial Jacinto Piquer dio orden de poner los cimientos de la iglesia en 1651, puesto que la cal necesaria se encontraba almacenada en la casa y se iba pudriendo cada vez mas.

En 1652, el padre Provincial, Diego de Alastuey, señaló que era conveniente reconsiderar la traza proyectada por el hermano Antonio Ambrosio. Según señalan las fuentes documentales, el diseño inicial no planteaba la comunicación de las capillas de la iglesia, colocándose los confesionarios en los lugares donde debía de establecerse la conexión entre las mismas. Alastuey indicó que estos tenían que emplazarse "donde [era] costumbre" en los templos de la Compañía, y que era conveniente establecer la intercomunicación de las capillas por el interior, una medida que facilitaría las confesiones, puesto que aquellos que acudieran a las mismas lo podrían "hacer con mas comodidad, y sin la molestia de andar por el tránsito vecino donde están los bancos de los hombres". Además, el Provincial indicó la necesidad de añadir "a la iglesia una capilla mas por banda", ${ }^{12}$ por lo que su- ponemos que el templo diseñado por el hermano Ambrosio debía de contar con dos capillas por lado. A pesar de tratarse de una solución poco frecuente, en la provincia aragonesa encontramos dos templos con el mismo número de capillas como las iglesias de los colegios de Alagón y Graus. En ambas, a estas dos capillas debe añadirse un tramo previo correspondiente al coro o tribuna situada a los pies que sin duda debía estar presente en este diseño. Suponemos que las indicaciones del Provincial debieron ser tenidas en cuenta, ya que la planta finalmente construida cuenta con tres capillas a cada lado con la apertura además de paso entre las mismas.

Somos testigos del interés de algunos ciudadanos por contribuir a la fábrica del nuevo templo, tal y como se había solicitado. Así, Catalina del Pozo, a su muerte el 9 de junio de 1653, legó al colegio quinientas libras para la construcción de una capiIla dedicada a San Ignacio y para la ejecución de su retablo "en la iglesia nueva que se edifica[ba]". ${ }^{13}$ En 1655 el mercader Pedro Pujadas donó catorce mil nueve libras para la fábrica, a condición de que se realizase una capilla dedicada a San Pedro. ${ }^{14}$ Por otro lado, entre el 16 de julio de 1658 y el 25 de julio de 1662 se emplearon en la fábrica 457 libras 8 sueldos y 1 dinero, procedentes de la hacienda de los padres Funes. ${ }^{15}$

Los trabajos prosiguieron gracias a estos fondos, hasta que, en 1668, la ciudad y el colegio procedieron a acordar nuevos límites para el entorno de la nueva construcción. En esta "moxonacion", los Jurados José Muñoz de Pamplona y José de la Raga, junto con el padre Rector, Urbano Campos, "midieron y limitaron los dichos espacios y vagos que son propios de dicho collegio". Se concretó, por ejemplo, el espacio que debía dejarse frente a la iglesia, fijado en seis varas y media, pudiéndose tomar hasta una "terçia" de la calle en caso de

\footnotetext{
9 El hermano Antonio Ambrosio (Italia, ? - desconocido, ?) aparece recogido en el catálogo segundo de la provincia aragonesa de 1651 como aptus ad officia praecipue ad aedificandur o un coadjutor apto para el oficio de la construcción (ARSI, Arag. 11, Catalogus $2^{\circ}$ Provincia Aragonia An 1651, f. 17r). La información del año 1652 en: RODRíGUEZ G. DE CEBALLOS, Alfonso, 1969, pp. 69-70. AZANZA LÓPEZ, José Javier, 1998, pp. 84, 128, 304.

10 Memorial del padre Francisco Franco, 19 sep. 1650, A.H.S.I.C., ACOB 007, s. f.

11 NAVARRO CATALÁN, David Miguel, 2002, p. 154.

12 "Se añadirá a la iglesia una capilla más por banda, se ahorrarán dos o tres mil ducados, porque las pilastras y estribos serán menos en número, y las personas, que se han de confesar lo podrán hacer con más comodidad, y sin la molestia de andar por el tránsito vecino donde están los bancos de los hombres" (Memorial del padre Diego de Alastuey, 20 oct. 1652, AHSIC, ACOB 007 , s. f.).

13 De algunos legados o vinculos que se dejan a este Colegio, AHN, Clero, Jesuitas, lib. 669, f. 462r.

14 RUBIO SEMPER, Agustín, 1980, p. 38.

${ }^{15}$ Estado temporal del Colegio etc. (1662), ARSI, Fondo Gesuitico, Collegia, 1381, Calatayud, 29.
} 
que se construyeran gradas para el acceso al templo, o bien una lonja o "tornacoche". ${ }^{16}$

En 1680, el Provincial Celidonio Arbicio ordenó, "para adelantar, y abreviar la fábrica de la iglesia nueva", terminar el cuerpo del templo, que se estableció tendría seis capillas colaterales. La capilla mayor seguiría siendo "de prestado", hasta que, más adelante, se procediera a la construcción del crucero "con su media naranja" y de la cabecera de la iglesia. Una vez que el cuerpo estuviera finalizado, el Santísimo Sacramento podría trasladarse a la iglesia y así los jesuitas podrían servirse de ella. Sin embargo, para 1693 las obras no habían avanzado lo requerido por el Provincial. Son claras a este respecto las palabras del padre visitador: "el edificio de la nueva iglesia ha largos años que está empezado habiéndose gastado en él muchos millares; es materia de mucho escrúpulo que estando la fábrica tan adelantada, se deje de proseguir". Encargaba encarecidamente al Rector bilbilitano, el padre José Campos, que procurara encontrar "el medio que puede haber de que se prosiga hasta cubrirla, y echar las aguas siquiera para que no se malogre y acabe de perder lo que está edificado". ${ }^{17}$

\section{José Urbiso y la capitulación para la obra del cuerpo de la nave (1700)}

El colegio de Calatayud se hallaba endeudado a finales del siglo $\mathrm{XVII}{ }^{18}$ por lo que transcurrieron unos años hasta que la casa pudo hacer frente a la continuación de las obras del nuevo templo. El 31 de mayo de 1700, el Rector José Antonio Martínez y los padres de la casa contrataron al albañil José Urbiso para proceder a la edificación del cuerpo de la iglesia. ${ }^{19}$ Actuaban así en línea con lo indicado por el padre provincial Gabriel Sierra, que, en noviembre de dicho año, ordenó continuar hasta "su ultima perfeccion" esta fábrica, hasta ponerla "en uso para consuelo de todo el lugar, y para quitar la suma incomodidad" que había supuesto el desempeño de los ministerios de la orden "en la cortedad y estrechura" del templo anterior. ${ }^{20}$
Según el documento de la capitulación, realizado ante el notario Juan Francisco de Yanguas, estos trabajos debían realizarse en el plazo de dos años, pagándose por ellos la suma de 580 libras. Las obras a realizar incluían la construcción de la nave central con sus capillas laterales, la elevación de los muros con sus tribunas, el cerramiento con la fábrica de las bóvedas y los tejados, y la ejecución de la fachada. Es decir, se encargó a José Urbiso la construcción completa del cuerpo de la iglesia, desde los pies de la misma hasta la altura del transepto, y desde la parte inferior de los muros hasta los tejados. Si bien sabemos que, en la práctica, las obras no alcanzaron el tercer tramo de la nave, anexo al crucero.

En el citado documento de la capitulación se estableció punto por punto todo aquello que tenía que ser construido y la manera en que esto debía hacerse, "segun buen arte y edificatoria". Este escrito se acompañó de un "Tratado de adornos de talla y arquitectura" en el que se hicieron constar los aspectos decorativos de la fábrica, parámetro cada vez más importante ya que a partir del primer tercio del siglo XVII la sobriedad que había caracterizado a las construcciones de la Compañía había empezado a dar paso a una mayor experimentación y aparato decorativo, dentro de la teatralidad del gusto barroco. La llegada al generalato de Paolo Oliva en 1664 había supuesto una nueva etapa en la normativa referida a las iglesias, realizando una nueva interpretación de las prescripciones de la Congregación General I recogidas en el Decreto "De Ratione Aedificiorum" con la conclusión de que los conocidos preceptos de austeridad y solidez habían sido previstos exclusivamente para los edificios de residencia y escuelas. Esta puntualización suponía, por tanto, una mayor libertad proyectual y decorativa en templos y capillas, que caracteriza gran parte de la producción arquitectónica jesuita a partir de la segunda mitad del s. XVII. ${ }^{21}$

\footnotetext{
${ }^{16}$ Acto realizado el 20 de agosto de 1668 ante el notario Juan Francisco de Yanguas. Moxonacion hecha entre la Ciudad de Calataiud y el Collegio de la Compañia de Jesus de dicha Ciudad, Archivo Histórico Provincial de Zaragoza (AHPZ), A-2202-2, 22, Censos y otros documentos referentes a la Comunidad de Calatayud y al Colegio de la Compañía de Jesús en dicha ciudad, s. f.). La palabra "tornacoche" hace referencia a un área previa al ingreso, con espacio suficiente para que un coche pudiera dar la vuelta.

17 NAVARRO CATALÁN, David Miguel, 2002, 154-155.

${ }^{18}$ Memorial del padre Manuel Piñeiro, 1 oct. 1697, AHSIC, ACOB 007, s. f.

${ }^{19}$ Censos y otros documentos referentes a la Comunidad de Calatayud y al Colegio de la Compañía de Jesús en dicha ciudad, Capitulacion de la obra de la Yglesia del Colegio de la Compañia de Jesus, AHPZ, A-2202-2,1, s. f. No conocemos otros datos sobre este maestro albañil, vecino de Calatayud o de Aranda (Zaragoza), quizás hermano de Bernardo Urbiso, albañil vecino de la segunda localidad, quien también se obligó en esta concordia junto a Juan Pérez, albañil vecino de Calatayud.

20 Memorial del padre Gabriel Sierra, nov. 1700, AHSIC, ACOB 007, s. f.

${ }^{21}$ RODRÍGUEZ G. DE CEBALLOS, Alfonso, 2002, pp. 30-31.
} 
También se incluyó un modelo y, al menos, una traza de la fachada, en los que el albañil encontraría los detalles no reflejados en el contrato. En el modelo se indicaron algunos de los materiales de construcción. Así, en color negro se señalaron los lugares en los que habría de emplearse la piedra de sillería. Esta sería extraída por cuenta del albañil de la "cantera alta", ocupándose de labrarla, "sacarla y debastarla", para que el colegio se encargara de llevarla a pie de obra. El ladrillo sería otro de los materiales principales a emplear. Las paredes debían construirse "del material que dara el Colegio se entiende piedra o ladrillo".

En primer lugar, se ordenó proseguir la fachada o el "frontis de la puerta" -cuyo primer cuerpo ya estaba construido-, hasta concluirla según el modelo y traza entregadas. Las basas de las pilastras del segundo cuerpo debían componerse de zócalo, bocel de media caña y filetes, continuando por los "resaltos y rincones", y se continuaría la "cornisilla" que, discurriendo bajo dichas basas, separaba ambos pisos. La fachada se decoraría con pirámides, manteniéndose en toda ella "el orden". Estas disposiciones coinciden con la fachada finalmente ejecutada, probablemente inspirada en el tratado de Andrea Pozzo, concretamente en las imágenes del hastial de la iglesia de San Fedele en Milán recogidas en el segundo volumen del Perspectiva pictorum et architectorum. La cronología refuerza esta hipótesis ya que la capitulación para la construcción de la fachada fue firmada en el año 1700, fecha posterior a la publicación del tratado de Pozzo. 22

En segundo lugar, Urbiso tenía que "proseguir y lebantar" los muros del templo, tanto los interiores, a ambos lados de la nave, como los exteriores, hasta la altura necesaria para "echar los rafes". Construiría los arcos del cuerpo de la iglesia, dando al arco toral cinco palmos de rosca, y a los restantes un ladrillo y medio. ${ }^{23}$

En las tribunas labraría en piedra una columna en medio de cada vano, flanqueándola a ambos lados por dos medias columnas con fustes lisos, todas con sus basas y capiteles compuestos, adornados estos "de talla y fruto y algun pedazo de trapo" o guirnalda. Sobre los capiteles correría "una cornisilla de orden compuesta de la proporcion que pide el arte". Las columnas, capiteles y basas debían labrarse "de piedra del genero que es la portada", piedra de color oscuro que debía ser si-

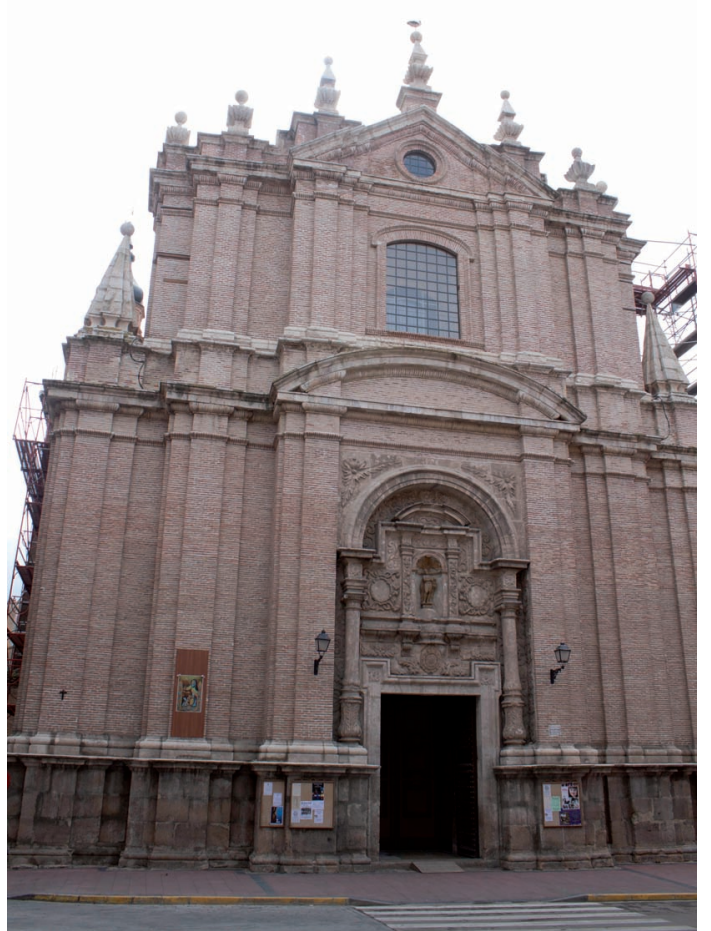

Fig. 2. Calatayud (Zaragoza). Antiguo Colegio de la Compañía. Fachada de la iglesia.

milar a la empleada en la ejecución del zócalo del portal. Como vemos, el contrato establecía la ejecución de tribunas bíforas como las que se habían construido en las iglesias jesuitas de Zaragoza o Tarazona y que se adoptarán posteriormente en la iglesia de Graus ya en el siglo XVIII.

La cornisa principal debía ser arquitrabada, "bien distribuida y semetriada de alto y buelo", con las molduras realizadas en yeso blanco. Se decoraría con modellones de talla mui garbosos, formando cada modillón un recuadro debajo del plafón. Sobre las pilastras tenía que llevar "tarjones" o tarjetones con colgantes de frutas y "talla de buen reliebe", resaltando la cornisa.

Sobre esta, el albañil debía hacer un banquillo de cinco palmos de alto, con una moldura formada por un bocel de media caña y filetes. Sobre el banquillo se dispondrían las ventanas, con sus recuadros y molduras propias.

\footnotetext{
22 CARRETERO CALVO, Rebeca, 2017, p. 126.

23 Todas las referencias a palmos recogidas en la capitulación hacen sin duda referencia a palmos aragoneses.
} 
A pesar de lo pormenorizado de la información, el documento no concreta el curioso orden adoptado en las pilastras del alzado de la nave. Se trata del llamado sexto orden u orden del hermano Bautista, cuyo capitel aparece integrado por una doble hilera de hojas de acanto integrada con un equino y ábaco liso a la manera dórica. Su presencia en una iglesia jesuita no resultaba en absoluto extraña, ya que fue utilizado ya en la primera mitad del s. XVII en San Juan Bautista de Toledo y San Isidro el Real de Madrid, ${ }^{24}$ apareciendo de manera habitual en edificios con vinculación mariana como las iglesias de las Calatravas y las Góngoras en Madrid hacia 1670 o de manera más temprana en 1658 en la iglesia parroquial de Valdemoro. ${ }^{25}$ También en las mismas fechas será empleado en el alzado de las fachadas de la Basílica de los Desamparados de Valencia, ${ }^{26}$ por lo que no debe resultarnos extraña su presencia en el alzado interior de la iglesia de un colegio dedicado a Nuestra Señora del Pilar.

Junto al Ilamativo capitel, el sexto orden se distingue por la presencia de modillones en el entablamento antes citada con el recuadro en forma de "ymoscapo o media caña" tal y como aparece detallado en la capitulación. Además, el texto establece que "es condicion que en todas las pilastras y arcos asi en los del cuerpo de la yglesia como en los de las capillas y tribunas a de correr sus" platabandas, como efectivamente corresponde al entablamento del orden del hermano Bautista cuyas dos platabandas son continuas tal y como fueron ejecutadas en la nave de la iglesia de Calatayud. Su alzado, además, constituye uno de los ejemplos más singulares dentro de la variedad de órdenes empleados en las iglesias jesuitas aragonesas. Si en fechas tempranas los jesuitas alternaron los órdenes dóricos y jónico en sus construcciones (como el toscano empleado en el templo de Tarazona acabado a comienzos de 1653), ${ }^{27}$ progresivamente fueron introduciendo otras variantes como el sexto orden o el curioso capitel inspirado en el orden divino del templo de Salomón adoptado en el templo de Graus. No debemos olvidar la relevancia del orden escogido en el alzado interior de las iglesias, ya que en los planos de los proyectos enviados a Roma debía figurar aparte de las indicaciones de carácter tipológico, el orden arquitec- tónico y los elementos decorativos presentes en el revoco de los templos, con la intención de controlar posibles excesos ornamentales y no permitir a los artífices añadir nuevos elementos. ${ }^{28}$

En cuanto a los sistemas de cierre del templo, tras "acer y plantar cuatro tigeras de ballesta con sus maças y abrazaderas de yerro", se haría el tejado. Especial atención merecía el sistema para desalojar las aguas de la cubierta: si era necesario, se construirían canales y arcos de piedra, a fin de que estas cayeran a la plaza delantera.

Urbiso construiría las bóvedas, tanto de la nave como de las capillas y de las tribunas, todas de cañón, echando también el suelo de las tribunas. Estas bóvedas aparecen de manera curiosa descritas en la documentación como "de media arista". Este término, inédito hasta la fecha, debe hacer sin duda referencia a las bóvedas de cañón con lunetos finalmente construidas. La expresión debe referirse a la particular geometría de estas bóvedas de cañón donde la profundidad de los lunetos corresponde a un tercio de la luz del tramo de cañón de la bóveda. En este caso, la profundidad de los lunetos hace que la geometría de la bóveda se aproxime a un tramo de arista. Las bóvedas debían ir lavadas de yeso pardo, por la parte cóncava, y "bien despalmadas", por la convexa. En cuanto a su decoración, tenían que ir fajeadas, y en el centro de cada una debía disponerse un entarxon o florón de talla de buen relieve, de catorce palmos de largo por la anchura que el albañil considerara adecuada para mantener una "buena proporcion". Estos florones se colocarían, también, en las bóvedas de las capillas, y tanto estos como las fajas tenían que ir lavados y lisos de yeso pardo.

Para finalizar, las paredes debían igualarse y lavarse, de yeso pardo primero, y blanco después. El suelo de la iglesia y de las capillas también tenía que enladrillarse, y se colocarían puertas y ventanas -cerradas con alabastros y vidrieras-, así como mesas de altar, si se consideraba necesario. La utilización de este material se recomendaba en las Instructiones de Borromeo donde se hacía referencia a la correcta iluminación de la iglesia para una adecuada celebración de los oficios, recomendando el cierre de los huecos con cristales traslúcidos. La ubicación de los ventanales del templo bil-

\footnotetext{
${ }^{24}$ KUBLER, George, 1957, p. 60.

${ }^{25}$ MARÍAS, Fernando, 1983, p. 32.

26 BÉRCHEZ GÓMEZ, Joaquín, 1995, p. 207.

27 CARRETERO CALVO, Rebeca, 2012, pp. 144-145.

28 VALLERY-RADOT, Jean, 1970, p. 15.
} 
bilitano coincidía de pleno con las recomendaciones del texto normativo donde se indicaba que la luz debía proceder de los ventanales situados en el testero de fachada, la parte alta de la nave y el presbiterio, dejando abierta la posibilidad de iluminación también desde el tambor de la cúpula, aquí abiertos en la base de la semiesfera. ${ }^{29}$

En el "rincón del crucero a la parte que al Colegio pareciere", se dispuso construir la sacristía, si bien, como veremos más adelante, esta no fue realizada en este momento. La sacristía, como en todo templo parroquial o conventual, era una de las estancias fundamentales en la cabecera de las iglesias jesuitas. La solución más habitual para la ubicación de esta pieza era ocupar uno de los dos espacios que flanqueaban el altar en el esquema arquetípico de cabecera rectangular. Curiosamente, el plano del hermano Forcada que mencionaremos seguidamente parece reflejar los dos emplazamientos posibles para la construcción de la sacristía ya que aparecen dos espacios de planta rectangular grafiados con el número 4 identificado en la leyenda como sacristía. Además, se debía continuar la pared que existía entre el espacio del cuerpo de la iglesia y el crucero, hasta servir de cimbra al arco toral. ${ }^{30}$

En la ejecución de estas obras, el albañil José Urbiso hubo de contar con la colaboración del hermano José Iraola, cantero guipuzcoano que "hizo patente la habilidad de su oficio en la portada, y tribunas de la Iglesia en construcción, piezas que adorna[ba]n mucho el todo de su magnifica fabrica". ${ }^{31}$

\section{Las obras del crucero (1748-1767)}

En las décadas de 1710 y 1720, la mala situación económica del colegio bilbilitano fue la causa de que únicamente pudieran realizarse en la nueva

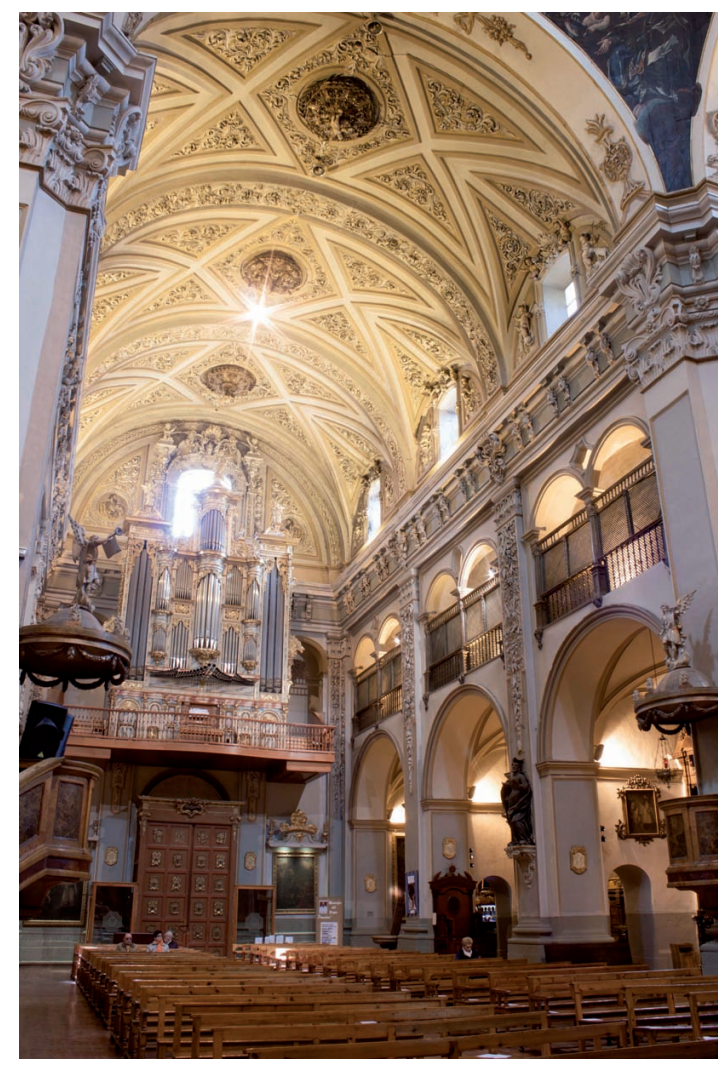

Fig. 3. Calatayud (Zaragoza). Antiguo Colegio de la Compañía. Iglesia. Vista del interior hacia los pies.

iglesia una serie de trabajos menores..$^{32}$ En ellos se emplearon el carpintero Juan Quílez, y un albañil, probablemente Juan Alcalde. ${ }^{33}$ Así mismo, se procedió a la compra de materiales para la construcción, llevándose al colegio en julio de 1716 gran cantidad de ladrillos, tejas y cal. ${ }^{34}$

\footnotetext{
29 BORROMEO, Carlos, 1577, pp. 13-14.

30 IBÁÑEZ FERNÁNDEZ, Javier; CRIADO MAINAR, Javier, 2012, pp. 456-458.
}

31 El hermano José Iraola (1670, Régil, Guipúzcoa-10 oct. 1729, Alagón, Zaragoza) era cantero en la vida secular, oficio en "el que salio eminente". Como tal llegó a Calatayud, y, tras tratar con los jesuitas, decidió ingresar en la orden en 1704, siendo admitido en el Colegio. Realizado el noviciado en Tarragona, regresó a Calatayud, donde, además de trabajar en la portada y tribunas de la iglesia, se dedicó a la procura de la casa. Después, fue enviado al Colegio de Manresa, para trabajar en la fábrica de la Santa Cueva, pero por motivos de salud fue destinado al Colegio de Huesca, donde se dedicó de nuevo a la procura. A continuación pasó al Colegio de Zaragoza, como administrador de la casa del Colegio en Monreal del Campo, y tras ello a la Residencia de Alagón, hacia 1727, empleándose en la administración de la hacienda (Cartas enviadas al Colegio de Gandía, comunicando la muerte de Religiosos de la Provincia de Aragón de la Compañía de Jesús, desde 1628 a 1766, ARV, Clero, Legajo 104, caja 237, s. f.).

32 Memorial del padre Gregorio Mayor, 1 jul. 1708, Memorial del padre Gregorio Mayor, 24 nov. 1709, Memorial del padre Antonio Rius, AHSIC, ACOB 007, s. f.

33 Entre 1715 y 1732 un libro de cuentas registra diversos pagos a un carpintero (1715-1716, 1719), a un albañil (1716, 1717, $1718,1720,1722)$, y a un tejero $(1716,1717,1723,1725,1727)$ (Cuentas con oficiales y criados del Colegio. Años 1688-1764, AHN, Clero, Jesuitas, lib. 585, s. f.), apareciendo relacionados con ellos los nombres de Juan Quílez y Juan Alcalde.

34 En concreto, mil "ladrillos comunes" valorados en cinco libras y seis dineros, ladrillos en cuadro por ocho libras, otros quinientos ladrillos y tejas, y cinco quintadas de cal (Cuentas con oficiales y criados del Colegio. Años 1688-1764, AHN, Clero, Jesuitas, lib. 585 , s. f.). 


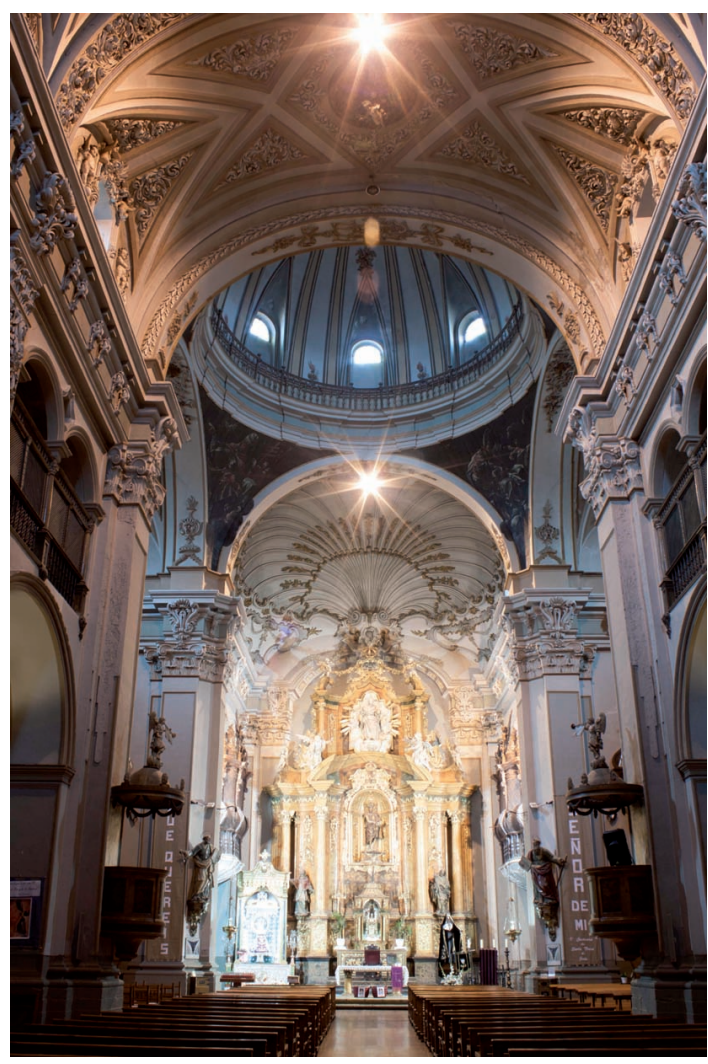

Fig. 4. Calatayud (Zaragoza). Antiguo Colegio de la Companía. Iglesia. Vista del interior desde los pies.

En 1729 se encargó la colocación de celosías en las tribunas, por motivos de "modestia y decencia", al igual que cambiar la disposición de la escalera del púlpito, ubicado junto a la capilla de San Francisco de Borja, por la misma razón..$^{35} \mathrm{El}$ requisito de privacidad quedaba garantizado por estos elementos de control visual, convertidos en habituales desde su colocación en los pequeños balcones o coretti de la iglesia madre del Gesú.

A partir de 1748 y hasta 1767, fecha de la Expulsión, el templo fue objeto de un nuevo impulso constructivo. ${ }^{36}$ Gracias al legado del presbítero José Ximeno de Meca, se pudo proceder a la construcción del transepto, con una cúpula sobre el crucero, del tercer tramo de las capillas (desde el ingreso), de la capilla mayor, con cabecera rectangular, y de la sacristía de la iglesia.

Además, se incorporó una nueva decoración rococó, y se colocaron los retablos del crucero y de la capilla mayor, dando como resultado "uno de los conjuntos arquitectónico-decorativos más rutilantes del rococó en Aragón".

El 10 de mayo de 1748 comenzaron las obras, que continuaron hasta su paralización en 1767, a causa del suceso de la Expulsión. En ese momento se estaban concluyendo los trabajos, que se dirigían a la decoración del interior del templo y a la dotación de retablos. En total, entre 1748 y 1767 se invirtieron 10.438 libras, 10 sueldos y 5 dineros en la construcción del templo. Como señala A. Ansón, el "estricto control" y la reconocida capacidad de los jesuitas como administradores y gestores, nos permiten conocer que en 1748 se emplearon 300 libras anuales en la construcción, llegando a la dedicar 4.559 libras en 1765, coincidiendo con el final de la obra, cuando se acometió el equipamiento del templo. ${ }^{37}$

En este punto debemos hacer referencia a la existencia de un plano de la planta baja del colegio, realizado hacia el año 1740 [Fig. 5]..$^{38}$ Este diseño recoge los dos espacios que conforman el conjunto colegial: a la izquierda, la iglesia, y adosadas a ella por el lado de la Epístola, las dependencias propias del colegio.

La planta de la iglesia dibuja una llamativa cruz latina, con una nave de tres tramos con capillas laterales entre los contrafuertes -en número de tres por lado y comunicadas entre sí-, transepto destacado con cúpula sobre el crucero y cabecera rectangular. La labor apostólica de la Compañía, centrada en las predicaciones públicas donde se exhortaba al auditorio a la práctica frecuente de los sacramentos, requiría un amplio espacio de congregación que permitiese albergar un número considerable de fieles con las adecuadas condiciones de acústica y visibilidad. Estos condicionantes establecían una clara preferencia por las trazas uninave recomendadas por los cánones del Concilio de Trento sin soportes intermedios que pudieran interferir en la visión del predicador, así como por las cabeceras rectangulares y bóvedas de cañón que garantizaban una mejor audición. A ambos

\footnotetext{
${ }^{35}$ Memorial del padre Vicente Juan, 2 jul. 1729, AHSIC, ACOB 007, s. f.

36 ANSÓN NAVARRO, Arturo; BOLOQUI LARRAYA, Belén, 1989, pp. 427-445.

${ }^{37}$ ANSÓN NAVARRO, Arturo; BOLOQUI LARRAYA, Belén, 1989, pp. 429-431.

38 El plano, en paradero desconocido, tiene unas medidas de 30 x 43 cms., y está coloreado en azul y marrón (FURLONG, Guillermo, 1959, p. 208).
} 
lados de la nave o naves laterales quedaban situadas las capillas laterales, dispuestas entre los estribos y comunicadas entre sí que permitían la celebración simultánea de misas privadas en los altares, además de la colocación de los confesionarios introducidos progresivamente en los templos de la Compañía, con lo que la distribución de los sacramentos de la Eucaristía o Penitencia podía ser eficaz a numerosos fieles. La presencia de estas capillas comunicantes o los espacios que flanqueaban el coro garantizaban una circulación periférica independiente de la nave reservada al público. ${ }^{39}$

El transepto saliente se diferencia del resto de iglesias jesuitas aragonesas que adoptan el modelo de la iglesia madre de la Compañía, el Gesú de Roma, con transepto enrasado en planta y poco habitual en los templos del resto de la provincia, con la destacada excepción de la iglesia de la casa profesa de Valencia. En el crucero el plano muestra la proyección del tambor poligonal así como el círculo de la semiesfera del interior de la cúpula finalmente construida. El diseño muestra también en la Capilla Mayor rotulada con el número 3 la proyección de las dos trompas que sirven de base a la llamativa venera que cubre la cabecera en este caso sin grafiar. Este elemento, único en las iglesias jesuitas aragonesas, y sin duda llamativo, se encuentra presente también tanto en el presbiterio poligonal de la iglesia del noviciado de Tarragona como en la cabecera semicircular de la iglesia del colegio de Belén de Barcelona incluidas ambas en la misma provincia eclesiástica.

A ambos lados de la capilla mayor se sitúan dos estancias rectangulares, a las que se accede tanto desde los brazos del transepto, como desde los laterales de la capilla mayor. La izquierda de estas dos salas, cuenta en su esquina superior izquierda con la planta de una torre de base cuadrada. Se trata de la estructura arquetípica tantas veces repetida en la cabecera de las iglesias jesuitas en la que se dispone el altar mayor flanqueado por dos espacios generalmente cuadrados situados en el nivel inferior de las tribunas, destinadas a albergar piezas como sacristía, estancias de servicio o constituir espacios de paso. Este planteamiento, adoptado en los principales templos de la provincia castellana (iglesias de los colegios de Monforte de Lemos, Salamanca o Colegio Real de Madrid) o toledana (iglesia de San Ildefonso en Toledo) es también el habitual en las iglesias aragonesas de planta contrarreformista (iglesias de Alagón, Huesca, Tarazona o Graus, aparte de la propia colegial de Calatayud). En el nivel superior, y a la misma cota

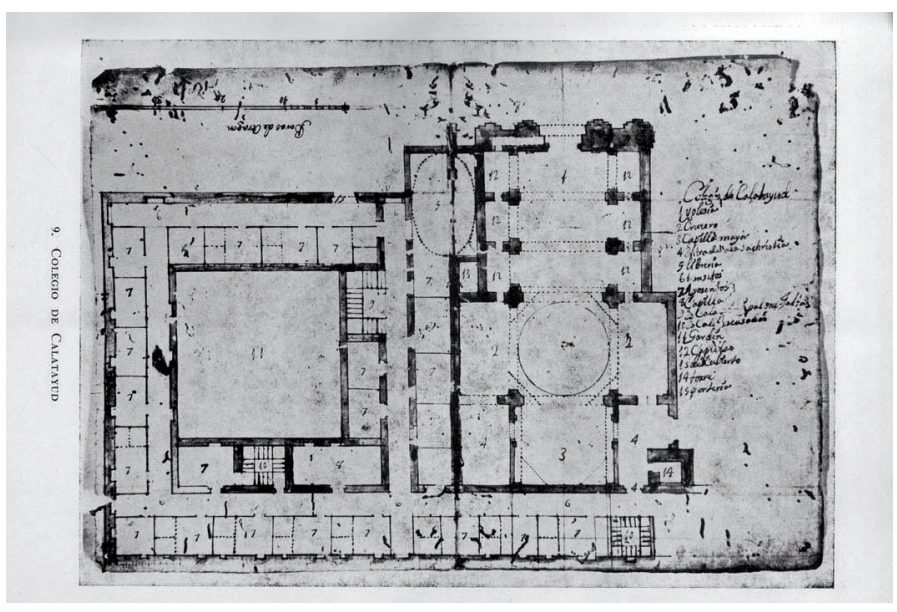

Fig. 5. Planta del Colegio de Calatayud según el Padre Forcada (FURLONG, Guillermo, 1959, p. 208).

que los locales de vivienda de la comunidad, se situaban las tribunas laterales reservadas a los padres tanto para la asistencia a los sermones como para sus visitas al Santo Sacramento. La solución adoptada en la colegial de Calatayud será también la más habitual, con dos tribunas cuadradas o rectangulares flanqueando el altar mayor repitiendo el esquema de la planta inferior.

En algunos casos como el que nos ocupa estas estancias o parte de las mismas podían servir de base de un campanario anexo a la cabecera. El número y emplazamiento de las torres campanario en las iglesias de la Compañía podía variar en cada caso. En las provincias castellana, toledana y andaluza predomina el esquema de fachada flanqueada por dos torres presente en la iglesia del Collegium Regium de Salamanca, San Ildefonso en Toledo, la iglesia del Colegio Imperial de Madrid o San Luis de los Franceses en Sevilla, así como en la inacabada fachada de la colegial de San Isidoro de Oviedo. Sin embargo, en la provincia aragonesa es más habitual la presencia de un único campanario, habitualmente ubicado sobre la primera capilla de uno de los lados como en la iglesia de San Carlos de Zaragoza, aunque no es infrecuente la existencia de campanarios anexos a la cabecera como el construido en San Juan el Real de Calatayud y finalizado después de la expulsión.

A los pies del templo, se encuentra la fachada, con dos grupos de pilastras flanqueando la puerta de acceso principal al mismo, con toda probabilidad

39 MOISY, Pierre, 1958, Tomo I, p. 326 
una representación simplificada de la fachada finalmente construida que debió ser reproducida en un diseño más detallado para su construcción. Aun así, el vano correspondiente a la portada aparece representado en un plano adelantado al lienzo de fachada aunque no aparece detallada la estructura de tres planos superpuestos. En su muro derecho se refleja un pequeño pasillo que debía dar acceso a las capillas laterales del lado de la Epístola nunca construido. Las dependencias colegiales están organizadas en torno a un claustro de planta cuadrangular. En torno a él se disponen los aposentos, que también discurren junto a un pasillo situado tras la cabecera de la iglesia. A la izquierda de la portería -señalada con el número 15- se dispone, tras atravesar uno de los pasillos, la librería (5), emplazada en una sala rectangular en la que se proyecta una bóveda oval. Junto a esta sala, detrás de su pared superior izquierda se dispone una pequeña estancia, también rectangular, que responde, según indica la leyenda, al descubierto (13) o patio de luces. Alrededor del patio central, en su esquina superior izquierda se emplaza la capilla (8), de planta rectangular. A su muro izquierdo se adosa la Escalera principal que falta (9), que establecería la comunicación con el piso superior, también accesible por dos cajas de escalinatas acusadas (10), ubicadas tanto en el muro superior del patio como en el extremo izquierdo de los espacios situados tras la cabecera del templo. ${ }^{40}$

Este plano fue realizado por el hermano jesuita Antonio Forcada. ${ }^{41}$ La similitud existente entre la traza de la iglesia y el resultado de las obras llevadas a cabo en el segundo impulso constructivo del templo, comenzado en 1748, ha llevado a diversas investigaciones a señalar al hermano Forcada como proyectista de esta fase constructiva de la iglesia, que, como se ha referido, supuso la elevación del último tramo de capillas de la nave, del transepto, de la cabecera y de la sacristía de la iglesia de Nuestra Señora del Pilar. ${ }^{42}$ La adopción de soluciones constructivas como la cúpula gallonada en el crucero, presente en iglesias de fundaciones en cuyas fábricas tomó parte Forcada como los colegios de Tarazona y Alagón parece reforzar la pretendida atribución al hermano coadjutor de las trazas del crucero. ${ }^{43}$ Sin embargo, otras investigaciones han especificado que Forcada pudo limitarse a copiar el proyecto, realizado por otra mano. ${ }^{44}$

40 La traza contiene la escala en Baras de Aragon, en la esquina inferior derecha, y la leyenda del plano, con sus estancias enumeradas, en el lateral izquierdo: Colegio de Calatayud / 1 yglesia / 2 Crucero / 3 Capilla mayor / 4 Entrada a la sachristia / 5 libreria / 6 transitos / 7 Aposentos / 8 Capillas / 9 Escala principal que falta / 10 Escalinatas escusadas / 11 Gardin / 12 Capillas / 13 descubierto / 14 torre / 15 porteria (ibidem, p. 208).

41 El hermano Antonio Forcada (Nuez de Ebro, Aragón, 22 mar. 1701-30 jun. 1767, San Ignacio Miní, Argentina) ingresó en la Compañía de Jesús en Zaragoza el 12 de septiembre de 1735. Realizó su probación en el Noviciado de Tarragona (1736), desde donde fue trasladado a los Colegios de Ontiniente (1737, 1739), Gandía (1740), Alagón (1741) y Tarazona (1742-1743). En 1743 fue destinado a las misiones de la Provincia de Paraguay, donde realizó su últimos votos el 5 de octubre de 1749 y donde fallecería. Arquitecto, intervino en la construcción de varias de las casas jesuitas aragonesas (ARSI, Arag. 13, ff. 401r, 434r; ARSI, Arag. 14, ff. 11r, 42r, 91r, 122v; ARSI, Arag. 15, ff. 323v, 326r, 337r, 346v, 368v, 378r, 387r-v, 392v, 401v; Féjer/De Cock, 1986, s. p.). El 23 de marzo de 1745 salió del Puerto de Santa María (Cádiz), llegando a Buenos Aires el 15 de julio de 1745 en la expedición de misioneros del padre Diego Garvía. Allí continuó desarrollando su papel de arquitecto, trabajando en los Colegios de Córdoba, Buenos Aires, Montevideo -para el que realizó dos proyectos- y Santa Fe (1745-1759). En las reducciones guaraníes (1759-1767) se ocupó del levantamiento de los pueblos de Jesús y Santos Cosme y Damián, diseñando y dirigiendo las obras de colegios e iglesias. Además, se le atribuyen un plano de la Universidad de Córdoba y se defiende su intervención en las iglesias de San Ignacio Miní (Argentina), San Ignacio Guazú y Jesús (Paraguay) y quizás en el colegio de Asunción (Paraguay). A Sudamérica llevó consigo un conjunto de once diseños, todos pertenecientes a edificios jesuitas de la provincia de Aragón -excepto los de los colegio de Madrid y Cádiz- entre los que se encontraban las plantas de los colegios de Tarazona, Alagón y Calatayud, realizados entre 1735 y 1745. Lamentablemente, estos planos, que debían conservarse en el Archivo del colegio de la Inmaculada de Santa Fe (Argentina), fueron expoliados, desconociéndose hoy día su paradero. Únicamente disponemos de las reproducciones publicadas en 1959 por Guillermo Furlong, quien los había dado a conocer unos años antes. Agradecemos al padre Martín Morales, Director del Archivo Histórico de la Pontificia Universidad Gregoriana, sus informaciones al respecto (FURLONG, Guillermo, 1933, p. 86. FURLONG, Guillermo; BUSCHIAZZO, Mario, 1942. FURLONG, Guillermo, 1959, láms. 5, 8 y 9. BOLOQUI LARRAYA, Belén, 1997, pp. 327-328. CARAMAN, Philip; McNASPY, Clement, 2001, pp. 1484-1485. IBÁÑEZ FERNÁNDEZ, Javier; CRIADO MAINAR, Javier, 2012, pp. 407-408, 412-414 y 421-422. LEVINTON, Norberto, 2012, pp. 281-282).

42 Así lo sostienen: ANSÓN NAVARRO, Arturo; BOLOQUI LARRAYA, Belén, 1989, pp. 431-432. BOLOQUI LARRAYA, Belén, 1997, pp. 329-330.

43 LEVINTON, Norberto, 2016, p. 95.

44 El padre F. B. Medina, como expuso en la conferencia impartida en Bogotá (Colombia) en el año 1998, sostiene que Forcada se limitó a reunir y copiar los planos "para que le sirvieran de pauta y modelo una vez en América". La presencia en el repertorio de las plantas de los colegios Imperial de Madrid y de Cádiz se explicaría porque este hermano los levantaría a su paso por estas ciudades camino a su partida desde el Puerto de Santa María (Cádiz). Por su parte, B. Boloqui señala la doble posibilidad de que Forcada fuera el autor del proyecto o se limitara a copiarlo (BOLOQUI LARRAYA, Belén, 1997, p. 328). 
El responsable de la puesta en marcha de este proyecto pudo ser el hermano José Galbán. ${ }^{45}$ Este jesuita residió en el colegio de Calatayud en 1747 y en 1748, años en los que ejerció como architectus en la casa. ${ }^{46}$ Su labor se vería continuada por el también arquitecto jesuita Francisco Martínez, un hermano que residió en la misma casa entre 1753 y $1764,{ }^{47}$ en un momento en que, como veremos, se estaba procediendo a la construcción de la cúpula sobre el crucero y se intervenía en las tribunas, entre otras obras. ${ }^{48}$

En cuanto al desarrollo de los trabajos en esta parte del templo, entre 1748 y 1752 se elevaron los muros del crucero y del presbiterio, encargándose las cimbras de las bóvedas al carpintero, ya mencionado, Juan Quílez. Entre 1752 y 1754 se levantó la cúpula sobre el crucero, cubriéndose su exterior con tejas vidriadas de colores en octubre de 1754. En junio de 1755 se procedió a realizar la misma labor con la linterna. A la altura de 1756 se estaban entablando las tribunas, tras lo cual los trabajos discurrieron con mayor lentitud. En 1761 se lucieron con yeso parte del interior de la iglesia y la cúpula.

Por tanto, si exceptuamos la construcción de la sacristía, efectuada entre 1761 y 1763, las obras enencaminadas a la conclusión del templo de Nuestra Señora del Pilar se llevaron a cabo entre 1748 y 1762, estando el crucero con la cúpula y el presbiterio finalizados "en lo sustancial" en el año 1756. ${ }^{49}$ Todo ello, siempre, bajo el control de los

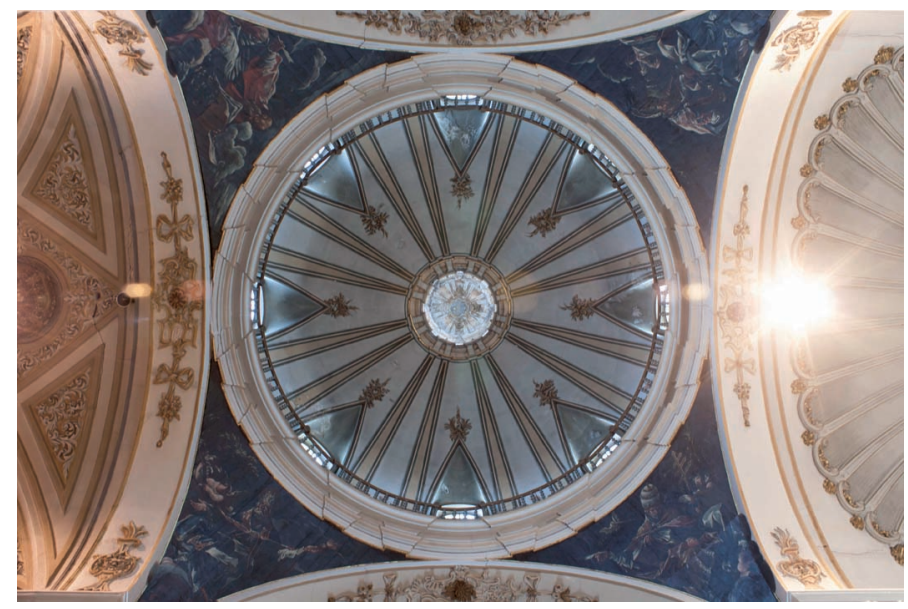

Fig. 6. Calatayud (Zaragoza). Antiguo Colegio de la Compañía. Iglesia. Detalle de la cúpula sobre el crucero.

padres Provinciales, que instaban a rematar la fábrica de la nueva iglesia. ${ }^{50}$

A esta fase constructiva, le siguió la decorativa. Desarrollada entre 1762 y 1767, su finalización se vio suspendida, como venimos repitiendo, por el episodio de la Expulsión. En relación a ella, en 1762 se completó la decoración de la cúpula con la colocación de una barandilla de madera dorada y claraboyas, mientras que entre 1763 y 1766 se procedió

${ }^{45}$ El hermano José Galbán (Uncastillo, Aragón, 19 jun. 1705-Calatayud, Aragón, 21 feb. 1766) ingresó en la Compañía de Jesús el 27 de enero de 1736, realizando los votos de coadjutor temporal formado el 2 de febrero de 1746. Residió en los colegios de Manresa (1737-1742 y 1763-1764), Huesca (1743-1745-1746), Calatayud (1747-1748), Tarazona (1749-1750), ¿Alagón? (1751) y Teruel (1753-1762), para finalizar su vida en el Seminario de Nobles de Calatayud (1765-1766). Arquitecto de profesión, intervino en la construcción de algunas de las casas citadas, vinculándose su figura igualmente con otros oficios domésticos propios de un coadjutor, como la sastrería (ARSI, Arag. 13, ff. 419r, 450v; ARSI, Arag. 14, ff. 30r, 60r, 90v, 120v, 149v, 163r, 242v, 274v, 329v, 371v; ARSI, Arag. 15, ff. 341v, 371r, 381r, 387v, 396v, 406r, 415r, 424v, 437v; ARSI, Arag. 16, pp. 24, 44, 38, 49; ARSI, Arag. 16a, pp. 27, 28, 30, 36, 40; ARSI, Arag. 17, pp. 9, 52. FÉJER, József; DE COCK, Joseph, 1986, s. p.). BRAUN, Joseph, 1913, pp. 107-108. BOLOQUI LARRAYA, Belén, 1997, pp. 328-331.

${ }^{46}$ ARSI, Arag. 15, ff. 415r y 424v. B. Boloqui señala que en 1746 Galbán ya se encontraba en el colegio bilbilitano (BOLOQUI LARRAYA, Belén, 1997, p. 329), un dato que no hemos podido confirmar.

${ }^{47}$ El hermano Francisco Martínez (Graus, Aragón, 28 may. 1710/1719-Valparaíso, Chile, 31 doc. 1767, o Rímini, Italia, 10 feb. 1771) ingresó en la Compañía de Jesús el 28 de noviembre de 1755, realizando los votos de coadjutor temporal el 2 de febrero de 1758. Residió en el colegio de Calatayud al menos entre los años 1753 a 1764, en su papel de "architectus". Tras 1764, pudo ser enviado fuera de la provincia aragonesa, bien a la Véneta o a la Peruana, falleciendo en uno de los dos lugares (ARSI, Arag. 14, ff. 223v, 255v, 306v, 348v, 390r; ARSI, Arag. 16, pp. 8, 12, 19; ARSI, Arag. 16a, pp. 6-9. FÉJER, József; DE COCK, Joseph, 1986, s. p.). BOLOQUI LARRAYA, Belén, 1997, pp. 331-332.

48 ANSÓN NAVARRO, Arturo; BOLOQUI LARRAYA, Belén, 1989, p. 432. BOLOQUI LARRAYA, Belén, 1997, pp. 331-332.

${ }^{49}$ En ellos se emplearon 150.662 ladrillos hasta 1760, comprados primero a tejeros de Terrer, y tras 1752 de Calatayud. Las tejas curvas vidriadas de la cúpula las realizó un tejero de Lumpiaque (Zaragoza), las de la linterna, planas, de lágrima y vidriadas, fueron obra de Joseph Moneva, tejero de Villafeliche (Zaragoza). ANSÓN NAVARRO, Arturo; BOLOQUI LARRAYA, Belén, 1989, pp. 432-433.

50 "16. He tenido gran complacencia, viendo cuan adelantada está la obra de la iglesia (...) deseo se continúe en ella con actividad, para que tengamos el gusto de ver concluída la iglesia lo más pronto que sea posible" (Memorial del padre Gabriel Juan, 15 oct. 1750, AHSIC, ACOB 007, s. f.); "9. Ultimamente encargo al Padre Provincial y al Padre Prefecto de la obra de la iglesia pongan toda eficacia en que se remate" (Memorial del padre Jaime Bou, 16 oct. 1758, AHSIC, ACOB 007, s. f.). 
a embaldosar el templo. Entre esos años se desarrollaron también trabajos de cantería, con piedra de Calatorao y Ricla, que fue empleada en el presbiterio, en las bases de las pilastras o en la lauda sepulcral del benefactor Rodrigo Zapata. En 1765 se colocaron azulejos de Villafeliche (Zaragoza) y Valencia. ${ }^{51}$

La iglesia quedó inconclusa debido al suceso de la Expulsión. La portada, la torre y el retablo mayor no pudieron ser finalizados. Además, algunos retablos laterales quedaron sin dorar. Una vez finalizada la portada, se colocó sobre el dintel de acceso el escudo del monarca que dictó la Expulsión, Carlos III. El campanario fue realizado entre los años 1774 y $1777 . .^{52}$

\section{La iglesia del Colegio de la Compañía de Jesús de Calatayud y los templos jesuitas españoles}

A mediados del s. XVI la Compañía española empezó a construir templos de nueva planta de un carácter meramente funcional. Se trataba de estructuras de una gran simplicidad, de planta rectangular uninave y dimensiones modestas, que en su práctica totalidad fueron sustituidos por templos de mayor tamaño. ${ }^{53}$ En un principio, la conocida pervivencia del gótico en la península durante el quinientos hace que numerosas iglesias jesuitas recurran aún a trazas medievalizantes con abovedamientos de crucería nervada, particularmente en la provincia aragonesa. ${ }^{54}$ Frente a iglesias como la del Colegio de San Esteban en Murcia con sencillas trazas de perfil rectangular con bóvedas de crucería, la planta de las iglesias de los colegios de Zaragoza y Montesión (Palma de Mallorca) recurre al arcaico esquema uninave con cabecera poligonal propio del gótico mediterráneo combinado con ojivas nervadas, con las capillas ubicadas entre los contrafuertes. Este esquema, arquetipo del templo gótico en la provincia aragonesa conseguía sin embargo dar respuesta a los requisitos funcionales de las iglesias jesuitas fundamentalmente por la presencia de capillas apropiadas para penitencias, cultos particulares y misas.
Junto a la pervivencia de la traza medievalizante, el modelo de iglesia contrarreformista establecido por la iglesia del Gesú ejerce ya una importante influencia en la arquitectura de la Compañía a finales del quinientos. En la provincia aragonesa la solución de Vignola será adoptada por vez primera en el diseño para la iglesia de la Casa Profesa de Valencia (iniciada en 1595) con un esquema uninave con capillas hornacinas y cúpula sobre tambor en el crucero matizado por con arcaísmos como la cabecera poligonal o las crucerías, que desaparecerán ya a principios del s. XVII en la más moderna iglesia del colegio de Gandía (principiada en 1605). La adaptación del plan postridentino es más rápida en la provincia castellana, donde la iglesia del colegio de Villagarcía de Campos (concluida en 1580) recurre al mismo plan uninave rectangular con testero plano, transepto cupulado sin tambor y bóvedas de cañón. El templo de Villagarcía de Campos ejercerá una influencia notable en la arquitectura de la provincia castellana hasta bien entrado el s. XVII. Así, la planta contrarreformista o jesuítica, adoptada en la construcción de las iglesias de Alcalá de Henares y Toledo (principios del s. XVII) es desarrollada en dos de los principales templos de la provincia, las iglesias del Colegio Real de Salamanca y del Colegio Imperial de Madrid, ambas con planta uninave con capillas hornacinas, crucero con cúpula sobre un pronunciado tambor y los vanos de las tribunas integrados en el alzado de la nave. Creemos que esta temprana adaptación del plan contrarreformista se convertirá en modelo para el arquetipo de iglesia jesuita aragonesa, con una planimetría similar a la que será adoptada en la iglesia de Calatayud salvo por el matiz del transepto saliente y la ausencia de tambor en la cúpula. Por su parte, la provincia andaluza juega un papel menos importante en la asimilación de este modelo, recurriendo los templos a un prototipo alternativo de planta rectangular con bóvedas vaídas o esféricas.

Ya en el s. XVII, las fundaciones aragonesas juegan un papel destacado en el proceso de evolución de la planta jesuítica. La temprana construcción de

${ }^{51}$ El crucero fue pavimentado con baldosas procedentes de Terrer, como las restantes. Por su parte, los trabajos de cantería costaron un total de 446 libras 12 sueldos y 9 dineros. ANSÓN NAVARRO, Arturo; BOLOQUI LARRAYA, Belén, 1989, pp. $432-433$.

52 MARCO IBÁÑEZ, Ángel, 1976, pp. 88-89. RUBIO SEMPER, Agustín, 1980, p. 38.

53 BRAUN, Joseph, 1913, p. 24.

${ }^{54}$ La pervivencia de la tradición constructiva gótica en países como España, Francia o Alemania hace que numerosas iglesias jesuitas muestren rasgos medievalizantes, como demuestran dos de las construcciones más relevantes de la Compañía en Europa como la iglesia de San Miguel de Munich, de traza uninave con cabecera poligonal o la iglesia de la Casa Profesa de París, abovedada con crucerías. La eficaz adaptación de las trazas arcaizantes a los usos y costumbres de la orden queda demostrada por la utilización de diversas iglesias de origen medieval donadas a la Compañía en las provincias francesas, respetando su estructura y realizando intervenciones de escasa magnitud en las construcciones. MOISY, Pierre, 1998, Tomo I, pp. 331-338. 
la iglesia de Tarazona establece un modelo que servirá de referencia para el diseño adoptado con posterioridad en Calatayud. Así, podemos establecer un arquetipo de iglesia jesuita aragonesa uninave con tres capillas, moderna bóveda de cañón con profundos lunetos, transepto enrasado en planta y cabecera rectangular que será adoptado sin apenas modificaciones en Tarazona, Alagón y Huesca. En la iglesia del colegio de Graus el número de capillas queda reducido a dos por banda, mientras que la iglesia del colegio de Calatayud presenta la particularidad del transepto saliente. ${ }^{55}$ Las tribunas se convierten en elemento habitual en los templos jesuitas aragoneses adoptando en la iglesia de Calatayud la característica forma bífora con dos vanos de medio punto ya existente en la iglesia de San Carlos de Zaragoza. Por su parte, los destacados cruceros con cúpula sobre tambor de las grandes templos de la provincia castellana no serán adoptados en las iglesias jesuitas aragonesas donde predomina el esquema de cúpula sin tambor.

El conocimiento de la existencia de la planta trazada por el Hermano Ambrosio hacia 1650 nos confirma que la iglesia del colegio de Calatayud fue una de las primeras en asumir el moderno plan jesuítico en una curiosa versión simplificada, similar además al diseño adoptado posteriormente en la iglesia del colegio de Graus. La planta del hermano Ambrosio con dos capillas por banda debió ser modificada adoptando la configuración más habitual de tres capillas tomando probablemente como modelo la iglesia de Tarazona. Creemos que la nave construida por Urbiso debe corresponder a un proyecto completo que incluye el crucero y que décadas después se lleva a cabo la construcción de la segunda fase incluyendo la ejecución del crucero ya entrado el s. XVIII. Pensamos además que la planta de Forcada se ajusta al trazado finalmente aprobado en la iglesia. Se trata en todo caso de uno de los templos aragoneses que adoptan el plan jesuítico, matizado por el pronunciado transepto que la diferencia de las plantas de Alagón, Huesca o Tarazona, además de la llamativa venera de la cabecera. Por último, el conocimiento de la fecha del documento de la capitulación firmada con José Urbiso (1700), confirma que la traza de la fachada del templo pudo ser efectivamente inspirada en el tratado del jesuita Andrea Pozzo.

\section{Bibliografía}

ANSÓN NAVARRO, Arturo; BOLOQUI LARRAYA, Belén:

"La renovación artística de la iglesia de los Jesuitas de de Calatayud, hoy San Juan el Real (1748-1767)". En: MARTín BUENO, M. et al. Actas del Segundo Encuentro de Estudios Bilbilitanos, vol. I. Calatayud: Centro de Estudios Bilbilitanos, 1989, pp. 427-445.

ANSÓN NAVARRO, Arturo; BOLOQUI LARRAYA, Belén. "Zaragoza barroca". En: FATÁS CABEZA, G. (coor.). Guía histórico-artística de Zaragoza. Zaragoza: Ayuntamiento de Zaragoza, Área de cultura y educación, Institución Fernando el Católico, 2008, pp. 249-333.

AZANZA LÓPEZ, José Javier. Arquitectura religiosa del Barroco en Navarra. Pamplona: Gobierno de Navarra, Departamento de Educación y Cultura, 1998.

BÉRCHEZ GÓMEZ, Joaquín. "Basílica de Nuestra Señora de los Desamparados (Valencia)". En: BÉRCHEZ GÓMEZ, J. (dir.). Monumentos de la Comunidad Valenciana. Catálogo de Monumentos y Conjuntos declarados e incoados. Tomo X. Valencia Arquitectura Religiosa. Valencia: Dirección General de Patrimonio Artístico. Consellería de Cultura, Educación y Ciencia, 1995, pp. 204-217.

BOLOQUI LARRAYA, Belén. "Artistas relacionados con Calatayud según el Archivo General de los Jesuitas en Roma. Datos documentales del S. XVIII". En BIELZA DE ORY, V. et al. Actas del IV encuentro de Estudios Bilbilitanos. Vol. I. Calatayud: Centro de Estudios Bilbilitanos, 1997, pp. 323-349.

BORROMEO, Carlos. Instructiones Fabricae et Supellectis Ecclesiasticae, Milán, 1577. Reed. de la $1^{a}$ parte Instrucciones de la fábrica y del ajuar eclesiásticos. Introducción, traducción y notas de REYES CORIA, Bulmaro. México D.F.: Universidad Nacional Autónoma, Imprenta Universitaria, 1985.

BRAUN, Joseph. Spaniens alte Jesuitenkirchen. Ein Beitrag zur Geschichte der nachmittelalterlichen kirchlichen Architektur in Spanien. Freiburg im Breisgau: Herdersche, 1913.

CARAMAN, Philip; McNASPY, Clement. "Forcada, Antonio". En O'NEILL, C. E. (dir.) et al. Diccionario histórico de la Compañía de Jesús, 2001, pp. 1484-1485.

CARRETERO CALVO, Rebeca. Arte y arquitectura conventual en Tarazona en los siglos XVII y XVIII. Tarazona: Centro de Estudios Turiasonenses de la Institución "Fernando el Católico", Fundación Tarazona Monumental, 2012.

CARRETERO CALVO, Rebeca. "Recepción del tratado del jesuita Andrea Pozzo en Aragón". Locus amoenus, 2017, n 15, pp. 117-138.

CRIADO MAINAR, Javier. "Contribución de la Compañía de Jesús al campo de la arquitectura y de las artes plásticas en el ámbito español e iberoamericano". En BETRÁN, J. L. (ed.), La Compañía de Jesús y su proyección mediática en el mundo hispánico durante la Edad Moderna. Madrid: Sílex, 2010, pp. 272-274.

FÉJER, József; DE COCK, Joseph. Defuncti tertii saeculi Societatis Jesu, 1740-1773, vol. I. Roma: Institutum Historicum, 1986.

FURLONG, Guillermo; BUSCHIAZZO, Mario "Arquitectura religiosa colonial. Historia y análisis de unos planos". Archivum Historicum Societatis lesu, tomo 1 , cuad. 2, Buenos Aires, 1942.

FURLONG, Guillermo. Los jesuitas y la cultura rioplatense, Montevideo, 1933.

FURLONG, Guillermo. "Algunos planos de iglesias y colegios de la Compañía de Jesús en España". Archivum Historicum Societatis lesu, 1959, Vol. XXVIII, pp. 205-208.

55 IBÁÑEZ FERNÁNDEZ, Javier; CRIADO MAINAR, Javier, 2012, p. 457. 
IBÁÑEZ FERNÁNDEZ, Javier; CRIADO MAINAR, Jesús. "La arquitectura jesuítica en Aragón. Estado de la cuestión". En: ÁLVARO ZAMORA, M ${ }^{\mathrm{a}}$ I. (coor.) et al. La arquitectura jesuítica. Actas del simposio internacional. Zaragoza: Institución Fernando el Católico, 2012, pp. 393-472.

KUBLER, George. Arquitectura de los siglos XVII y XVIII. Ars Hispaniae, vol. XIV. Madrid: Plus Ultra, 1957.

LEVINTON, Norberto. Arquitectura de la Compañía de Jesús en Buenos Aires. La creación y el paso inclemente del tiempo. Buenos Aires: Contratiempo Ediciones, 2012.

LEVINTON, Norberto. "La escena urbana como estrategia apostólica. Un aporte trunco de la Compañía de Jesús para Montevideo". IHS. Antiguos jesuitas en Iberoamérica, 2016, vol. 4, nº 1, pp. 91-106.

MARCO IBÁÑEZ, Ángel. "Los jesuitas en Calatayud". Cuadernos de Aragón, 1976, n 8-9, pp. 81-93.

MARÍAS, Fernando. "Orden y modo en la arquitectura española". En: FORSSMAN, E. Dórico, Jónico, Corintio en la arquitectura del Renacimiento. Bilbao: Xarait Ediciones, 1983, pp. 7-45.

MARTÍNEZ VERÓN, Jesús. Arquitectos en Aragón: diccionario histórico. 5 vols. Zaragoza: Institución Fernando el Católico, 2000-2001.

MOISY, Pierre. Les Églises des jésuites de l'Ancienne Assistance de France. 2 vols. Roma: Institutum Historicum Societatis lesu, 1958.

MORALES GÓMEZ, Juan José. "Notas para una geografía urbana histórica de Calatayud. La localización de la parroquia de San Salvador, el Estudio de Artes y el barrio de Cantarranas". Turiaso, 2010-2011, n²0, pp. 159-170.

NAVARRO CATALÁN, David Miguel. "Introducción a la arquitectura jesuítica: la Provincia de Aragón". Anals de la Real Acadèmia de Cultura Valenciana, 2002, $n^{\circ} 77$, p. 137-157.

RODRÍGUEZ G. DE CEBALLOS, Alfonso. Estudios del barroco salmantino. El Colegio Real de la Compañía de Jesús (1617-1779). Salamanca: Centro de Estudios Salmantinos, 1969

RODRÍGUEZ G. DE CEBALLOS, Alfonso. La arquitectura de los jesuitas. Madrid: Edilupa, 2002.

RUBIO SEMPER, Agustín. Estudio documental de las artes en la Comunidad de Calatayud durante el siglo XVII. Zaragoza: Centro de Estudios Bilbilitanos, Instituto Fernando el Católico, 1980.

VALLERY-RADOT, Jean. Le recueil des plans d'edifices de la Compagnie de Jésus conservé a la Bibliothèque Nationale de Paris. Roma: Institutum Historicum Societatis lesu, 1970.

\section{Apéndice Documental}

\section{0, Mayo, 31, Calatayud}

Capitulación y concordia establecida entre el Colegio de la Compañía de Jesús de Calatayud y el albañil José Urbiso para la obra de la iglesia de dicho Colegio, ante el notario Juan Francisco de Yanguas.

AHPZ, A-2202-2,1, Censos y otros documentos referentes a la Comunidad de Calatayud y al Colegio de la Compañía de Jesús en dicha ciudad, Capitulacion de la obra de la Yglesia del Colegio de la Compañia de Jesus, s. f. /r/ Primero el frontis de la puerta lo a de proseguir y concluir conforme demuestra el modelo sin ynobar en el otra cosa mas que las basas de las pilastras del segundo cuerpo an de ser compuestas de un zocalo bocel media caña y filetes siguiendo todos los resaltos y rincones. Asimismo la cornisilla de debaxo las sobredichas basas esta la mitad hecha tenga obligacion de acer lo que falta del mismo modo que lo que ai echo. Asimismo si pareciere darles a las piramides [tachado: que de] otra y de aqui pareciere mas airosa tenga obligacion de acerlas del modo que se le diere la traca y prebiniendo que en todo se a de guardar el orden segun lo que demuestra menos en lo que se eceptua, se sigue tanbien que todo lo que demuestra el modelo de negro es piedra de silleria y a de ser de la cantera alta y el oficial o oficiales que prosiguieren dicha obra tengan obligacion de labrar y asentar por su quenta. toda la piedra ya mismo sacarla y desbastarla en la cantera y por quenta del colegio solo correra el traerla questo se entiende lo mismo con la piedra que sera menester para las tribunas.

/ $/$ Yttem es condicion que a de proseguir y lebantar todas las paredes de tribunas y cuerpo de yglesia a la altura necesaria para echar los rafes que seran conforme demuestra el modelo sino es en caso que al colegio pareciere poner otras molduras.

Asimismo tenga obligacion de acer los arcos del cuerpo de la iglesia prebiniendo que el arco toral que a de acer a de tener cinco palmos de rosca y los otros de un ladrillo y medio y de paflon lo que tienen las pilastras y a dichos arcos a de lebantar sus estribos todo lo que fuere necesario. todas las paredes seran de el material que dara el Colegio se entiende piedra o ladrillo o de anbas cosas.

Asimismo sobre la cornisa principal que ai formada en la yglesia a de acer su formacion de banquillo de cinco palmos de alto con sus molduras segun se dice en el tratado de adornos y arquitectura que todo corre por quenta del oficial que aga la obra.

/r/ Ittem es condicion que con la madera que le dara el Colegio aia de acer y plantar cuatro tigeras de ballesta con sus maças y abrazaderas de yerro. fieles y botareles que esten bien ensambladas a par y nudillo dandoles a dichas tixeras el pendiente necesario. y echas y plantadas las tigeras en madera para acer el texado con la madera que para esto dara el Colegio todos los texados los a de acer a cerro lleno. y encima de los estribos de los arcos ara tanbien sus texados a cerro lleno corriendoles sus rafes como a los demas texados si no es que pareciere minorarlos en algo.

es condicion que hecho lo sobredicho ara y bolbera las bobedas de todo el cuerpo de la yglesia capillas y tribunas todas de media arista y en el piso de las tribunas echara sus bueltas y suelo que fuere menester.

Las bobedas an de quedar todas labadas de yeso pardo por la parte concaba y conbexa bien despalmadas. dichas bobedas an /v/ de llebar dos alfas. El 
ladrillo todo el adorno y arquitectura que an de llebar dichas bobedas se bera en el tratado de adornos.

Los texados que caen a la parte del Colegio de las tres capillas se aran y formaran de la manera mas conbeniente para que puedan salir con mas facilidad las aguas y si para poner algunas canales de piedra o de otro genero son menester acer algunos arcos de piedra de Baldearenas de pared a pared de las tribunas tenga obligensen de acerlos y todas las cinbrias que seran menester para arcos y bobedas como tan bien reglas para las bobedas tenga el oficial obligacion de acerlas por su quenta dando el Colegio madera para ello.

Ittem es condicion que echo lo sobredicho a de ygualar todas las paredes guardando sus pesos y despues començar a labar toda la dicha fabrica por la parte de adentro començando desde arriba. toda de yesso pardo y rasparla y despues de labada de /r/ yesso pardo la bolbera a labar de yeso blanco pasandola el paño y dexandola toda bien lissa todas las molduras y arquitectura que a de llebar dicha fabrica se bera en el tratado de adornos.

Ittem es condicion que en las tribunas a de poner y labrar una coluna en medio de cada una y media coluna en cada lado con sus basas capiteles y demas adorno como se dice en el tratado de adornos que todas las colunas basas y capiteles an de ser de piedra del genero que es la portada.

Las bentanas de sobre el banquillo de los dos lados y del frontis seran segun demuestra el modelo.

En las bobedas de las capillas ara una demostracion de arco en cada una de tres palmos de paflon que serbira de cerramiento a los retablos de cada capilla el adorno que llebaran dichos arcos y lo demas de las capillas a de ser lo que se dice en el tratado de adornos que todo correra por quenta del oficial que aga la obra.

Iv/ Ittem es condicion que echo y concluido lo sobredicho a de enladrillar todo el suelo de la yglesia y capillas dexandolo bien zalosado.

Asimismo a de asentar todas las puertas bentanas alabastros y bidrieras que fueren necesarias y a de acer mesas altares si fueren menester.

Ittem es condicion que en el rincon del crucero a la parte que al Colegio pareciere tenga obligacion de acer sacristia del tamaño que fuere necesaria con sus bueltas y texado y que dichas bueltas y paredes de la sacristia an de quedar labadas como todas las demas de la yglesia que a dicha sacristia le aras y asentadas las bentanas y puertas necesarias dandole entrada o entradas necesarias para el Colegio aciendole sus escalas donde fuere mas conbeniente.

Ittem es condicion que en toda dicha fabrica se aian de guardar sus maciços pesos y perfiles que se necesita segun buen arte y edificatoria y que despues aia de ser bista y reconocida de nuestros peritos por anbas partes.
Ittem es condicion que dicha fabrica la a de dar concluidas en dos años si no es que el Colegio dexe de darle los materiales que en este caso se podra prolargar otro tanto tierpo [sic] como se le tarda a dar los materiales.

Ittem es condicion que el maestro o maestro que hubien de acer dicha obra lo primero an de obligarse y dar fianza y a contento del Colegio y que el Colegio a de dar cada semana o cada mes lo que se tiene gastado de oficiales y peones. y no otra cosa.

Iv/ Para dicha fabrica a de poner todos los tablones que tiene para andamios capaços para el yeso cestas para piedra y poçales y que el oficial a de traer las herramientas que a menester de paletas picos y legonas que a mas de la madera que el Colegio tiene para andamios le falta alguna cosa lo aia de traer de su cuenta.

Ittem es condicion que si alguna cosa en esta capitulacion falta que adbertir y fuere necesaria para que la fabrica quede ermosa y bien rematada tenga obligacion el oficial de acerlo sin poder pidir mejora alguna y lo mismo que se dice de esta capitulacion se dice en orden al tratado de adornos pues todo a de correr por quenta del oficial. Prebienese tan bien que para sacar las aguas de la mitad del cuerpo de la yglesia con sus texados de tribunas que todas an de salir a la plaça por la parte que cae al Colegio se an de acer canales de piedra mal/r/tosa alta tenga obligacion de sacar la piedra que sea buena para el intento y del vacio y ancho necesario para que puedan bien recebir el agua y el Colegio tendra obligacion de traerla y el oficial que hiciere la obra la obligacion de sacarlas debastarlas y labrarlas aciendoles sus encajes mas con otras como mas conbenga para la permanencia de que no se pase el agua y enbetunar tambien las juntas con buen betun el asentarlas tanbien correra por quenta del oficial como tan bien el acer unos arcos como ya esta prebenido para ponerlas.

Asimismo a de acer puertas o passo segun benga para pasar a las bobedas asi del cuerpo de la yglesia como de las sobretribunas, la pared que ai de tapia que dibide el cuerpo de la yglesia y crucero se a de continuar del mismo modo asta que sirba de cinbria del arco toral.

/v/ En casso que al Colegio pareciese que las sobre dichas canales no aian de ser de piedra sino de texones en este casso se disfalcara del concierto lo que prudencialmente se juzgare podrian costar.

En las colunas y medias colunas de las tribunas se an de acer sus arcos de medio ladrillo de recios con sus molduras segun se dice en el tratado de adorno.

Prebienese que las cedulas se traigan diciendo por quanto se ara la obra con toda la canteria o por quanto la aian sin canteria para admitirla el Colegio como mas bien juzgue le conbiene y puede ser que al oficial tanbien le este mejor el admitirla sin canteria.

Tratado de adornos de talla y arquitectura. 
Primero es condicion que las colunas y medias colunas que se an de caer en las tribunas dichas colunas an de llebar basas anti cargas y capiteles compuestos y las cañas lisas y en diferentes puestos adornadas de talla y frutos y algun pedazo de trapo. Y los pedestales de dichas colunas an de llebar basa y cornisa y los netos baciados con entalon alrededor. $Y$ encima de los capiteles de dichas colunas a de correr una cornisilla de orden compuesta de la proporcion que pide el arte.

Es condicion que en el arrancadero de los arcos de las capillas a de correr una cornisilla alquitrabada bien distribuida y de la proporcion que pide el arte y correra dicha cornissa por toda su circumbalacion asta encontrar en contra arco que aia tres palmos de profundidad para enbeber $/ \mathrm{v} /$ los retablos y esto es en todas las capillas.

Ittem es condicion que las bobedas del cuerpo de la yglesia y capillas an de yr fageadas y en medio de cada bobeda a de acer entarxon de talla de buen reliebe de la mejor que se use. Y cada tarxon de las bobedas del cuerpo de la iglesia a de tener catorce palmos de largo y de ancho lo que necesite para estar en buena proporcion. Los florones o tarxones que tanbien se an de acer en cada bobeda de capilla se le dara la proporcion que mas conbenga para el puesto y tanbien an de ser de talla de buen reliebe y a los unos y a los otros tarjones los ciñiran las faxas con la maior ermosura posible. Las fajas y tarxones quedar labados y bien lisos de yesso pardo.

La cornissa principal a de ser alquitrabada bien distribuida y semetriada de alto y buelo se le dara lo que pide el arco $/ r /$ y se le correra sus molduras de yeso blanco. Dicha cornisa a de estar adornada de modellones de talla mui garbosos y cada modellon forma un recuadro de bajo el paflon con un ymoscapo o media caña y en los maciços de las pilastras a de llebar tarxones de talla con unos colgantes de frutas y talla de buen reliebe $y$ an de ir puestos encima tenpanillos y dicha cornisa a de resaltar en los machones.

Ittem el banquillo de sobre dicha cornisa a de ir moldeado lisso que su moldura sera en bocel media caña y filetes. Resaltando en sus puestos necesarios.

Ittem es condicion que sobre los arcos rebajados de la [sic] tribunas an de correr sus molduras conforme demuestra el modelo.

Ittem es condicion que en todas las pilastras y arcos asi en los del cuerpo de la yglesia como en los de las capillas y tribunas a de correr sus platabandas.

Los arquillos que se an de acer en las tribunas an de ir moldeados por toda su circumbalacion alquitrabados.

Ittem es condicion que las bentanas que se an de acer sobre el banquillo asi las de los lados de la iglesia como las del frontis se an de acer como se demuestran en el modelo con sus recuadros y molduras obserbando en todo los pesos y perfiles que pide el buen arte.

En 31 de Mayo de 1700 se obligo Josef Urbiço que concerto la obra en 580 libras y asi mismo se obligo Juan Perez albanil becino de Calatayud y Bernardo Urbiço albañil vecino de Aranda y esta comanda esta para el cumplimiento de esta capitulacion. Notario Juan Francisco de Yanguas. 